Conference abstract PPAT06

\title{
Kinetic Pathway Analysis of Aggregation of Therapeutic Proteins
}

\author{
U. ROessl ${ }^{1,2}$, J. Wiesbauer ${ }^{1,2}$, S. Leitgeb ${ }^{1,2}$, B. NidetzKY $^{2}$ \\ ${ }^{1}$ Research Center Pharmaceutical Engineering GmbH, Graz, Austria \\ 2 Institute of Biotechnology and Biochemical Engineering, University of Technology Graz, Graz, Austria \\ E-mail: Ulrich.roessı@rcpe.at (U. Roessl) \\ Sci Pharm. 2010; 78: 695 \\ doi:10.3797/scipharm.cespt.8.PPAT06
}

\begin{abstract}
Protein aggregation represents probably the most common and troubling manifestation of protein instability. Shelf life of therapeutic proteins is particularly impaired by aggregation, which can occur almost in all phases of protein drug development. Administration of protein aggregates may lead to reduced pharmacological activity and adverse drug reactions. Thus, prediction of protein aggregation is of major interest for pharmaceutical industry. Existing sequence based bioinformatic tools are barely able to predict the aggregation behavior of therapeutic proteins. To implement new approaches for this, detailed analysis of protein aggregation, its underlying mechanisms and its kinetics is necessary.

In our study we simulate process conditions for induction of aggregation of a common therapeutic protein (granulocyte colony stimulating factor, G-CSF). Size exclusion HPLC is performed to quantify protein aggregates and to enable kinetic pathway analysis by identification of different aggregation intermediates under certain process and formulation conditions over time. Further characterization is accomplished using intrinsic fluorescence, polyacrylamid gel electrophoresis and mass spectrometry.
\end{abstract}

This work was supported by FFG, Land Steiermark and Steirische Wirktschaftsförderung (SFG). 